\title{
La Triple Frontera como centro de atracción del yihadismo en América Latina: Orientación teórico-histórica*
}

\author{
Johana Pérez Calderón**
}

Recibido: 18 de enero de 2016

Evaluado: 10 de marzo de 2016

Aceptado: 1 de abril de 2016

\section{Resumen}

Este escrito analiza, desde una orientación teórico-histórica, la amenaza que representa para la región de América Latina la existencia de movimientos islamistas radicales, células durmientes de grupos terroristas yihadistas y los nexos de grupos criminales sudamericanos con el yihadismo en la zona de la Triple Frontera (TF). Para cumplir este objetivo, se busca dar una respuesta a una pregunta que se ha vuelto muy recurrente: ¿es el terrorismo empleado por los movimientos yihadistas una amenaza real para América Latina? Una posible respuesta se inspira en el paradigma teórico-histórico: el constructivismo y el referente de la globalización. En síntesis, este paradigma constructivista explica las dudas que se tienen para acometer en la construcción de soluciones integrales para el manejo de la amenaza yihadista en la zona de la TF.

Se toma como referente a esta zona trifronteriza debido a que es considerada el mayor foco de amenaza en la zona del Cono Sur para el asentamiento del yihadismo, pues es un polo de atracción de actividades ilícitas. Allí se encuentra el crimen organizado, liderado por las mafias de las diferentes etnias que conviven en este espacio geográfico, como la árabe y la china; además permea una corrupción generalizada. Estos son los mayores peligros en

\footnotetext{
Este trabajo es producto de la investigación: Islam Radical: Amenaza para la Seguridad Nacional de Colombia en el marco de la guerra hibrida, de la línea: "Inteligencia y Contrainteligencia Estratégica" adscrita al Grupo de Investigación en Guerra Asimétrica CIGA de la Escuela de Inteligencia y Contrainteligencia Bg Ricardo Charry Solano. DOI: http://dx.doi. org/10.15332/s1794-3841.2017.0027.05

** Maestrante en Inteligencia Estratégica. Profesional en Relaciones Internacionales y estudios políticos de la Universidad Militar Nueva Granada. Profesora-Investigadora de la Escuela de Inteligencia y Contrainteligencia, Bogotá. johana23__@hotmail.com
} 
la zona, producto de las reticencias que crean escenarios atractivos y vulnerables que son aprovechados por el terrorismo internacional.

Palabras clave: Triple Frontera, Yihadismo, terrorismo islámico, constructivismo. 


\section{Triple-border as center of Yihadism attraction in Latin America: a theoretical-historical orientation}

Received: January 18, 2016

Evaluated: March 10, 2016

Accepted: April 1, 2016

\section{Abstract}

This article analyzes from a theoretical - historical orientation, the threat that represents for the region of Latin America the existence of islamist radical movements, sleeping cells of yihadist terrorist groups and the links of criminal South American groups with the yihadismo in the zone of the Triple Border. To fulfill this aim, a response is sought to give to a question that appellant has turned very: is it the terrorism used by the movements yihadistas a royal threat for Latin America? A possible response, it inspires by the theoretical - historical paradigm: the constructivism and the modal of the globalization. In synthesis, this paradigm constructivist explains the doubts that are had about attacking in the construction of integral solutions for the managing of the yihadist threat in the zone of the Triple Border.

It takes as a modal to this zone trifronter, due to the fact that South is considered to be the major area of threat in the zone of the southern cone for the accession of the yihadism, for being a pole of attraction of illicit activities, where the organized crime led by the mafias of the different ethnicities that coexist in this geographical space, as the arab and the small stone, permeated by a widespread corruption, being these the major dangers in the zone for the reticences of which they believe attractive and vulnerable scenarios that are taken advantage by the international terrorism.

Keywords: Tri-border, Yihadism, Islamic terrorism, constructivism. 


\section{A Tríplice Fronteira como centro de atração do jihadismo na América Latina: Orientação teórico-histórica}

\section{RESUMO}

Este escrito analisa, desde uma orientação teórico-histórica, a ameaça que representa para a região da América Latina a existência de movimentos islamitas radicais; células dormentes de grupos terroristas e jihadistas e os nexos de grupos criminosos da América do Sul com o jihadismo na zona da Tríplice Fronteira (TF). Para cumprir este objetivo, busca-se dar uma resposta a uma pergunta que tem sido recorrente: é o terrorismo empregado pelos movimentos jihadistas uma ameaça real para América Latina?

Uma possível resposta inspira-se no paradigma teórico-histórico: o construtivismo e o referente da globalização. Em síntese, este paradigma construtivista explica as duvidas que existem para acometer na construção de soluções integrais para o manejo da ameaça jihadista na zona da TF.

Toma-se como referente a esta zona trifronteiriça devido que é considerada como o maior foco de ameaça na zona do Cone Sul para o assentamento do jihadismo, ora, é um polo de atração para atividades ilícitas. Ali se encontra o crime organizado, liderado pelas máfias das diferentes etnias que convivem neste espaço geográfico como a árabe e a chinesa; além permeia uma corrupção generalizada. Estes são os maiores perigos na zona, produto das reticências que criam cenários atrativos e vulneráveis que são aproveitados pelo terrorismo internacional.

Palavras-chave: Tríplice Fronteira, jihadismo, terrorismo islâmico, construtivismo.
Recebido: 18 de janeiro de 2016

Avaliado: 10 de março de 2016

Aceito: 1 de april de 2016 


\section{INTRODUCCIÓN}

La zona geográfica de la Triple Frontera - TF - se localiza en la ciudad argentina de Puerto Iguazú, la ciudad brasileña de Foz de Iguazú y la ciudad paraguaya de Ciudad del Este. La región es una intersección geográfica de dos grandes ríos: el Río Paraná y el Río Iguazú. Paraguay se ubica al oeste del Río Paraná, Argentina al sur del Iguazú y Brasil al norte (Keshabarz, 2015).

Comúnmente, los Estados han entendido el control fronterizo como el trabajo y el derecho soberano que ejerce cualquier Estado para limitar el ingreso de amenazas en su territorio. No obstante, una vez terminada la Guerra Fría y con la imposición de la lógica de la globalización, la percepción de la amenazas cambiaron porque las fronteras parecieron deteriorarse, en razón a que los efectos de la interconexión humana también conectaron la percepción de amenaza e inseguridad de los Estados.

Nuestra problemática parte de un hecho reciente. Tras los atentados del 11 de septiembre de 2001 en New York, se avivó un debate entre los analistas de seguridad a nivel mundial, especialmente en los del continente americano, sobre el peligro que podría representar el nuevo terrorismo internacional empleado por grupos yihadistas islámicos para la seguridad del hemisferio occidental. Años atrás, dos atentados terroristas de gran trascendencia en Buenos Aires, en 1992 y 1994, pusieron en alerta al contexto latinoamericano al confirmarse que el atentado contra la Asociación Mutua Israelita Argentina AMIA había sido orquestado por la organización shiita libanesa, Hezbollah (Caro, 2007).
Los yihadistas han utilizado en los últimos años una retórica con reafirmaciones alusivas a la identidad islámica que reivindica un Estado Islámico y un nuevo orden mundial caracterizado por la inclusión del orden político musulmán en el Derecho Público Internacional - separado del orden político westfaliano, basado en el equilibrio de poderes y en la separación de la religión y la política-. Todo ello expuesto como un claro alambicamiento antioccidental. Por tal razón, los yihadistas han instado por aunar el refuerzo de la identidad islamista radical entre sus partidarios, formando identidades asesinas, que se instalan en asumir una actitud intolerante, dominante e incluso suicida dentro de sus simpatizantes. Esto queda reflejado en la máxima yihadista "amamos la muerte tanto como ustedes aman la vida" (Sohr, 2015, p. 25)

Habitualmente, en la naturaleza de los grupos $\mathrm{u}$ organizaciones criminales que emplean métodos terroristas está la búsqueda de escenarios propicios para el sostenimiento económico de la organización y el desarrollo de nuevos operativos. La zona de la $\mathrm{TF}$, por sus condiciones políticas, sociales y culturales podría ser considerada una región ideal para el alcance de sus fines de carácter internacional, por grupos yihadistas que operan de manera transnacional como Al Qaeda y sus grupos afiliados, Hezbollah y el autodenominado Estado Islámico, etc. Sus objetivos son políticos (establecer un Estado Islámico y extender el califato), económicos (el sostenimiento y mantenimiento del Estado), y religiosos (defender, expandir e imponer la religión del islam).

Ahora bien, al presentar y explicar, desde una perspectiva teórico-histórica, la amenaza 
que representa para la región de América Latina la existencia de movimientos yihadistas en la TF, el paradigma constructivista explica las dudas que tienen los gobiernos para acometer en la construcción de soluciones integrales para el manejo de la amenaza que representa el terrorismo yihadista en la zona de la TF.

Para cumplir el objetivo de este documento, el texto se divide en tres partes: la primera, en la cual se describe conceptualmente la ideología del salafismo yihadista; la segunda, en la cual se analizan los principales riesgos a los que deben hacer frente los países que comparten lindes en la zona de la TF con respecto al terrorismo yihadista. En la tercera, a partir de la tensión internacional ocasionada por el yihadismo, se plantea una propuesta desde el paradigma del constructivismo, para el diseño de una estrategia multilateral que permita contrarrestar esta amenaza en la TF.

\section{UNA INTERPRETACIÓN SOBRE EL YIHADISMO}

El concepto yihad suele traducirse y confundirse incorrectamente con el concepto medieval de guerra santa. El Corán no hace mención a la yihad de forma literal, sino que lo hace en relación al combate. En árabe, la palabra yihad significa esfuerzo y, en el contexto del Corán, en beneficio de la religión o esfuerzo por la fe (Torres, 2007).

Teóricamente, el término abarca un amplio abanico de esfuerzos que deben hacer los musulmanes por el islam. Por ello, debe distinguirse entre la yihad menor -yihad-e-Akbar- y la yihad mayor -yihad e Asgar-. La yihad mayor es la más importante y es aplicada por todos los musulmanes. Esta hace referencia al esfuerzo que debe hacer cada musulmán contra sí mismo, para luchar contra su propio ego, las malas inclinaciones y las tentaciones, en razón de purificar su alma.

Por otra parte, la Yihad menor que es empleada por grupos terroristas islámicos y se entiende como:

La lucha que se libra en defensa propia contra un enemigo que ha iniciado el ataque. Es también un esfuerzo para hacer frente a un enemigo que, de forma ilícita, expulsa a la gente de sus casas y se interpone frente a la libertad de adorar a Dios (Comunidad Musulmana Ahmadiyya, s.f, p.1).

En este sentido, la yihad menor es asociada con la lucha bélica y el uso de las armas, como un esfuerzo que hacen los musulmanes que tienen una ideología radical. Por ende, los que emprenden la yihad se enfocan en hacer una interpretación literal de ciertos versículos del Corán que hacen alusión al combate justo contra aquellos que atacan a los musulmanes. Claro está, el Corán determina que esta lucha armada solo será legitima en condiciones de defensa: "luchad por la causa de Dios contra quienes luchan contra vosotros, pero no transgredáis. En verdad, Allah no ama a los transgresores" (Corán 2:191).

Desde los inicios del islam en el siglo VII, las personas que se adhirieron a la comunidad musulmana fueron sometidas a persecuciones y a violencia física por parte de otras religiones -cristiana y judía especialmente-. A partir de ello, emergió el término Yihad. El profeta hizo el llamado a la yihad en el 
siglo VII y no descansó de ella hasta el día de su muerte en el año 632 d.c. Lidió varias campañas militares, aproximadamente 90 -las más destacadas, la Batalla de Badr, la de Uhud y la Batalla de la Fosa- por medio de las cuales consiguió que el islam ganara nuevos seguidores $\mathrm{y}$, también, el control sobre la península arábiga, expulsando a judíos y cristianos de la zona (Torres, 2007).

Como el versículo del Corán anteriormente citado, existen en este texto sagrado un sinnúmero de revelaciones de la vida del profeta que hacen referencia al contexto bélico y al carácter armado del comienzo de la religión en el siglo VII. Tales versículos han sembrado en algunas de las escuelas del islam el concepto islámico de la yihad menor, entendida como la lucha bélica por la causa islámica en sentido religioso ${ }^{3}$. En este marco, el término "salaf" significa ancestro, hace referencia a una ideología islámica sunnita que promueve el regreso a los orígenes del islam y a reencontrarse con la esencia de la religión, haciendo alusión a los cuatro primeros califas, al considerar que aquella pureza que comprendía al islam en aquella época hizo posible su expansión.

En la actualidad existen dos corrientes modernas que explican la ideología salafista. La primera, el salafismo de predicación, es llevada a cabo particularmente por los imanes próximos al régimen saudí y qatarí,

3 Sheij Mansur Mota, imán del Centro Cultural Islámico de Valencia, afirma que las condiciones bajo las que un musulmán puede ir a la guerra: "que la declare un gobernante o jefe de Estado reconocido y que esta tenga un carácter defensivo o solidario frente a una invasión" (Como se citó en Calleja, 2016).

"Combatid en los meses sagrados si sois atacados; porque la violación de lo sagrado esta [sujeta a la ley] de justa retribución. Si alguien comete una agresión contra vosotros, atacadle como os ha atacado y manteneos consciente de Dios, y sabed que Dios esta con los que son conscientes de él" (Corán, sura 2, 194). los cuales se rehúsan al yihadismo por su condición violenta y defienden la predica de la fe islámica. La segunda, el salafismo yihadista o Qutbismo, se niega a limitarse en la predicación y promueve el combate armado para liberar a los países musulmanes de cualquier invasión extranjera (Yihadistas, 2014).

En este sentido, uno de los primeros en emplear el término salafismo yihadista fue Abu Muhammad Al Maqdisi, con una propuesta dirigida a su estancia en Afganistán en 1984. Este representó un islam más radical e intolerante, que incorpora elementos antioccidentales e internacionalistas. Esta ideología denota un carácter violento y lo liga al acto religioso.

No obstante, la mayoría de musulmanes no son salafistas y la mayoría de salafistas no son terroristas. Con la denominación yihadista se da lugar a quienes de modo catártico y sintiéndose a la vanguardia del islam se pronuncian por medio de la lucha armada, conciben como obligación inapelable la necesidad de acometer una lucha armada en defensa de sus propias creencias contra toda aquella agresión externa por parte de los enemigos seculares, los infieles y los traicioneros de la religión.

De esta manera, la obsesión por hacer una interpretación violenta del islam es percibida por los musulmanes radicales como la manifestación más sublime de la fe en Allah, por el compromiso en el cumplimiento de sus mandatos. Por lo menos así fue expresado por uno de los ideólogos más importantes del yihadismo defensivo en el periodo contemporáneo y cofundador de Al Qaeda, Abdulá Azzam (como lo cita Torres, 2007) "cualquiera que no lleve 
a cabo la yihad hoy día está abandonando su deber, al igual que cualquiera que coma durante el Ramadán sin excusa, o el rico que no da limosna" (p.59).

\section{EXéGESIS DEL TERRORISMO YIHADISTA}

Para la comprensión del actual terrorismo internacional de inspiración yihadista se requiere de un análisis más específico sobre sus fundamentos ideológicos. Los analistas más destacados en asuntos de islamismo y de terrorismo yihadista en la actualidad, Gilles Kepel, Olivier Roy y Marc Sageman, plantean que el terrorismo yihadista logra articularse basándose en 3 elementos fundamentalmente: "la ideología yihadista, las circunstancias sociales que facilitan su difusión, el papel de los pequeños grupos locales y los lazos que les unen a la red terrorista global" (Avilés, 2005, párr. 10).

La yihad terrorista global se basa en una lectura salafista del islam y lo constituyen solo una minoría de la umma -comunidad islámica mundial-. Como se mencionó anteriormente, el salafismo hace referencia a una ideología que tiene pretensiones de devolver al islam la pureza de sus orígenes, fundamentándose en la lectura literal del Corán y las Sunnas -revelaciones de los dichos, hechos y asentamientos del profeta Mahoma y de su manera de proceder-y "rechazan no sólo todas las innovaciones derivadas de la influencia occidental, sino también toda la cultura que los musulmanes han venido elaborando con posterioridad al momento fundacional" (Avilés, 2005, párr. 11).

Esta vuelta de los musulmanes a sus orígenes se puede conseguir por dos vías. La primera, a través de la predicación -dawao a través del combate -yihad-, dirigido contra el enemigo cercano (los falsos musulmanes) o el lejano (los infieles). Los propagandistas actuales del salafismo yihadista, el líder fallecido de Al Qaeda, Osama Bin Laden y su actual líder Al Zawahiri, líder actual del autodenominado Estado Islámico, Abu Bakr al- Baghdadi, han dado prioridad al enemigo lejano.

Por tanto, el terrorismo que actualmente han orquestado grupos como Al Qaeda y el autodenominado Estado Islámico ha sido fundado en la difusión de la ideología yihadista, para que personas aparentemente normales cometan atrocidades basándose en la ideología extrema del salafismo yihadista: "que genere marcos de alineamiento colectivo, aunque la ideología por sí sola tampoco constituya una explicación satisfactoria a la violencia" (como lo cita Jordán, 2009, p. 199).

\section{Riesgos en la Triple FronterA}

\section{Relación entre actividades ilícitas y el crimen organizado trasnacional}

Desde hace más de una década, esta zona ha aumentado su relevancia y peligrosidad como el área donde se llevan a cabo múltiples actividades criminales que parecen concentrarse en su gran mayoría en el contrabando, la falsificación y el narcotráfico. La llamada TF se constituye por múltiples relaciones económicas, sociales, políticas, laborales y culturales y por la presencia de actores de diversa naturaleza que lo configuran como un espacio transnacional marcado por países que comparten lindes; 
además, por la extrema porosidad de sus fronteras, hace que compartan problemas colectivos entre sí, como la pobreza, la desigualdad y la inseguridad. Esta última, promovida esencialmente por organizaciones de crimen organizado que se sitúan en la zona y que operan trasnacionalmente (Fogel, 2008).

Según Emanuele Ottolengi, sénior de la Fundación para la Defensa de las Democracias FDD (como se cita en Silvero, 2016) indica que "el ambiente permisivo de la TF anima a los carteles criminales y al terrorismo para cooperar en beneficio mutuo y con ello poder financiar sus actividades ilícitas" (párr. 4). En consecuencia, tal como afirma Alda, "estas actividades ilícitas son en buena parte monopolizadas por el crimen organizado y han incidido en los niveles de violencia $y$, por consiguiente, en la seguridad pública" (Alda, 2014, p. 58).

De esta manera, las características particulares de la zona hacen de esta un epicentro de actividades comerciales ilegales, dadas en un marco de instituciones débiles y corrupción generalizada. Lo anterior se explica, al menos en parte, en que la actividad económica de la zona se concentra en Ciudad del Este -Paraguay- y Foz de Iguazú, estimando que Ciudad del Este, cuenta con la tercera mayor zona de libre comercio del mundo, después de Miami y Hong Kong; además, posee una infraestructura vial, portuaria, aeroportuaria y bancaria que facilita el intercambio comercial con Puerto Iguazú y Foz de Iguazú.

A lo anterior, se suma la generosa legislación fiscal y aduanera en Ciudad del Este. Esta tiene aranceles de importación más bajos; allí, los artículos que ingresan son reexportados a Argentina y Brasil, gracias a la débil aplicación a los derechos de aduana. Esta situación atrae constantemente a comerciantes extranjeros y, por consiguiente, a organizaciones de crimen organizado trasnacionales las cuales "motivadas por la alta rentabilidad de los negocios en la zona y la permisividad institucional, hacen de la zona un centro de operaciones y un punto neurálgico de las actividades ilícitas en Suramérica"(Bello, 2013, p. 103).

No por casualidad esto favorece a que se cree una relación simbiótica entre grupos terroristas yihadistas y organizaciones de crimen organizado, basada en utilidades mutuas e intereses comunes. Esto produce un fuerte impacto en la seguridad regional, pues facilita los medios logísticos y financieros que hacen posible que los grupos terroristas diseñen y ejecuten acciones que les permitan lucrarse y financiar sus acciones criminales. Por tanto, el comercio ilegal en la zona, junto con las actividades criminales, producen enormes ganancias y distorsiona las relaciones políticas y sociales no solo de Argentina, Brasil y Paraguay, sino de la región en general. Es preciso resaltar, como lo afirma Fabio Sánchez (2011) que:

Debido a la globalización de los mercados financieros internacionales, los grupos terroristas utilizan diversas modalidades para financiarse y ocultar el lucro procedente de diversas actividades delictivas. Algunas de estas organizaciones funcionan como multinacionales, con una logística específica y compuesta por personas, armas e itinerarios definidos (p.25).

A su vez, las actividades criminales otorgan poder político, influencia social y conexiones 
sociales. Considerando que hoy día las organizaciones criminales han identificado que el crimen proporciona una serie de motivaciones que no son necesariamente económicas (acceso a la autoridad, legitimidad), la sociedad encuentra protección en la red criminal en las zonas grises donde no hay presencia estatal. Finalmente, colaboran en la generación de identidad. En este sentido, "los grupos yihadistas se aprovechan de una manera simbiótica del tejido social diluyéndose en el mismo y creando una dinámica social, política y económica que facilita la ejecución de actividades criminales" (Fuente, 2014, p. 14).

Es así como las concepciones teóricas de Louis Shelley y John Picarelli, sobre la relación entre el crimen organizado trasnacional y el terrorismo, son de gran utilidad para explicar la presunta relación entre estos dos fenómenos y la TF. Los autores afirman que estos dos actores suelen adoptar métodos similares y operan con fines semejantes: funcionan utilizando una estructura en red, redes de células organizadas lo cual les permite tener flexibilidad organizativa, reduce la penetración de la ley y proporciona una mayor eficiencia, además de ello, utilizan todas las formas de tecnología moderna para ejecutar sus operaciones con un nivel de riesgo mínimo (Shelley y Picarelli, 2002).

\section{Corrupción}

En la TF se ha evidenciado una abismal interrelación entre las actividades ilícitas, el crimen organizado y la corrupción de funcionarios públicos. Esta última ha permitido que se desarrollen actividades ilícitas en la zona, que son el fruto de los altos niveles de corrupción política que existen, en particular en Paraguay, lo que facilita la acción de las organizaciones criminales y por consiguiente, de grupos yihadistas. Según el informe sobre la percepción de la corrupción publicado por la Organización para la Trasparencia Internacional (2015), Paraguay se ubica en el puesto 130 de un total de 167 países estudiados. Entre los países sudamericanos es el segundo país más corrupto, superado únicamente por Venezuela.

Lo anterior, en razón a que el régimen autoritario que instauró en Paraguay el mandatario Alfredo Stroessners hasta 1989 trajo consigo un fuerte sistema de corrupción en todos los sectores del gobierno. No obstante, el Estado actualmente intenta recuperarse de décadas de corrupción institucionalizada. Empero, la inestabilidad política y el fuerte sector empresarial han disuadido los esfuerzos, donde el soborno y la extorsión han impregnado todos los niveles del Estado. Donde los principales sectores y zonas afectadas por la corrupción han sido el sistema judicial, el sector hidroeléctrico, agrícola y la educación (Organización para la Trasparencia Internacional, 2015).

La corrupción generalizada ha sido aprovechada por el crimen organizado y por las mafias para ganar espacios de poder, abriendo las puertas a que la cultura criminal influencie y condicione a la cultura civil en la $\mathrm{TF}$, ya que no es suficiente poseer poder económico si no se detenta de poder político. De hecho, el poder político brinda al crimen organizado reconocimiento en la sociedad, y les permite adquirir legitimidad frente al tejido social. Ciertamente, la debilidad estatal, caracterizada por la ausencia de institucionalidad, y la excepcionalidad ante la ley han sido los frutos de la corrupción existente en la zona. 
En este caso, la corrupción es un factor determinante para que grupos yihadistas incrementen las posibilidades de influir en las decisiones estatales y lograr de esta manera, la protección de parte de los representantes políticos y de las autoridades de seguridad. Este apoyo estatal se convierte por tanto en una cuestión trascendental para afianzarse y prosperar en la región (Alda, 2014).

\section{Flujos migratorios}

La convergencia de las fronteras de Paraguay, Brasil y Argentina han hecho de la TF una región con una realidad sociopolítica compleja, donde habitan en forma estable más de 500.000 personas (International Organization for Migración, s.f.). El auge comercial de la TF inició en la década de los 70, con los proyectos para la construcción de la represa hidroeléctrica de Itaipú -represa binacional entre Paraguay y Brasilla construcción de la presa de Yacyreta y el establecimiento de la zona franca en Ciudad del Este en Paraguay. Dichos proyectos fomentaron nuevos poblamientos y el fenómeno migratorio en la TF, donde aún se destaca el movimiento regular e irregular de personas procedente de diferentes naciones, por la extrema porosidad de las fronteras. "Se calcula que entre 1971 y 2001 la población tri-lateral pasó a ser de $60 \mathrm{mil} \mathrm{a}$ 700 mil habitantes" (Bartolomé, 2002, p. 63).

Por ello la TF es una zona, pluriétnica, plurinacional y multicultural. De los $700 \mathrm{mil}$ habitantes:

Un porcentaje no menor, cercano al $10 \%$, corresponde a la suma de árabes (principalmente libaneses) y chinos-taiwaneses, quienes por cierto controlan (conjuntamente) gran parte de las actividades comerciales del eje Ciudad del Este-Foz de Iguazú (Bartolomé, 2002). Además de estas dos comunidades, de sólida presencia y considerable arraigo, existe una población algo más fluctuante de coreanos, japoneses, indios, y de diferentes países de Suramérica (Bello, 2012, p. 104).

En este marco, en el modelo de las migraciones internacionales y los flujos de mano de obra, la teoría de expulsión atracción -push and pull- establece que hay una lista de factores que provocan la expulsión de los nacionales de sus países de origen -malas condicioneseconómicas, socialesy políticasy unos factores de atracción, que hacen que los emigrantes se sientan atraídos por un país y no por otro -ventajas comparativas con respecto a otras naciones, Estados más desarrollados-. Tales factores son las causas que determinan la magnitud y direccionalidad de los flujos migratorios (Lacomba, 2001).

Las oleadas migratorias, para el caso de estudio, fueron producto del panorama geopolítico de los países de origen, considerando que ocurrieron de manera posterior a conflictos bélicos, en particular los que provenían de la región de Medio Oriente, pues sus países quedaron fragmentados y a la merced de la violencia ${ }^{4}$. Ello produjo la migración forzada de árabes a America Latina. Tanto Argentina como Brasil y Paraguay recibieron en su mayoría a migrantes sirios

4 Entre los conflictos se destacan la Primera Guerra Mundial, la Segunda Guerra Mundial, el conflicto árabe-israelí por la instauración del Estado de Israel, la irrupción de Israel en el Líbano y en buena parte del territorio de Palestina, entre otra serie de guerras que acontecieron. Incluso, en el presente, dadas las circunstancias bélicas que actualmente acontecen en Siria, se han generado masivos flujos migratorios de sirios a diferentes partes del mundo. 
y libaneses mientras que Paraguay fue receptor en su mayoría de palestinos. Por ello, hoy día "un gran porcentaje del comercio que abunda en la ciudades fronterizas ubicadas en la TF son atendidos por árabes" (BBC, 2005, párr. 23).

Si bien existe poca evidencia de que grupos terroristas exploten sistemáticamente los flujos migratorios para llevar a cabo atrocidades, es evidente que las políticas migratorias excesivamente restrictivas sí pueden crear condiciones propicias para el terrorismo, pero no hay que dejar de lado que los migrantes establecen circulación de flujos desde y hacia los países de origen, por los que atraviesan bienes, capitales y servicios. Por tanto, las autoridades migratorias de los tres países objeto de nuestro estudio, deberán caracterizar los criterios que prevalecen en el control fronterizo de la TF y tener en cuenta entre ellos el sensible tema de la seguridad nacional y regional, y no exclusivamente considerar prevenir el ingreso de personas indocumentadas.

Ahora bien, comoindica Schulmeister, "no se trata de estigmatizar a ninguna comunidad en particular, sino de identificar factores en el diagnóstico de la situación -en este caso, el demográfico- de los cuales los grupos grupos yihadistas se valen" (Schulmeister, 2004, p.19). El principal factor de diagnóstico es el arribo migratorio, el riesgo de que se produzca la incursión de organizaciones criminales y de miembros de grupos yihadistas; además, que en el flujo de capitales circule dinero proveniente de actividades económicas ilegales, producto de las actividades que realiza el crimen organizado y mafias ubicadas en la zona de los que hacen parte, por ejemplo, "agrupaciones de libaneses que están radicados en la zona como la mafia de las marcas, la Yakuza japonesa y las mafias china, taiwanesa entre otras que aprovechan el intercambio generado por los migrantes" (Bello, 2012, p. 104).

Ciertamente, el riesgo reside, en buena parte, en las políticas migratorias y legales de Paraguay, que han sido permeadas por una cultura de corrupción en las autoridades competentes y en las laxas leyes de migración en el país, que generan un fenómeno de inseguridad en los tres países ${ }^{5}$. En suma, las fronteras, al no ser estáticas, requieren del esfuerzo de los Estados para evitar el ingreso a la zona de actores trasnacionales clandestinos, crimen organizado, terroristas, etc.

\section{ESTRATEGIA CONTRA EL YIHADISMO EN LA TRIPLE FRONTERA}

\section{Fortalecimiento de los procesos de integración regional a partir de la teoría del constructivismo}

A lo largo del tiempo, diversas teorías han derivado en el desarrollo de políticas de seguridad y los gobiernos han promovido su implementación. A partir de los ataques terroristas del 11 de septiembre de 2001, orquestados por Al Qaeda en Estados Unidos, se produjo una fuerte reestructuración en el control de las fronteras, especialmente por parte del gobierno estadounidense para combatir al nuevo enemigo. Los gobiernos de Paraguay, Brasil y Argentina reestructuraron las medidas de seguridad con la

\footnotetext{
5 Los países se conectan entre Puerto Iguazú y Foz de Iguazú por el puente Tancredo Neves, Foz de Iguazú y Ciudad del Este se comunican por el puente de la Amistad y Ciudad del Este y Puerto de Iguazú se comunican por medio del rio Paraná.
} 
creación del Comando Tripartito de la Triple Frontera y el Grupo 3+1, que incluye a los gobiernos mencionados y a Estados Unidos, para reforzar la seguridad en la TF. En este marco, para encontrar respuestas teóricas al escenario anteriormente mencionado, se hace una reflexión con base en la teoría del constructivismo y en el referente de la globalización.

La teoría del constructivismo permite explicar las reticencias que se interponen para avanzar de manera eficiente y eficaz en la construcción de soluciones integrales para el manejo del control en las fronteras que comparten los Estados de Argentina, Brasil y Paraguay. Entre las premisas de esta teoría, se señala que la percepción de identidades, normas y de la cultura juegan un papel importante en la formulación de las políticas relacionadas con la seguridad. Uno de los factores más determinantes para la formulación de estrategias en la TF es el cultural, pues se insiste en considerar a los musulmanes y a los árabes que ingresan por esta zona como un riesgo para la seguridad nacional de los Estados inmersos. Esto ha incidido en el clima antimusulmán y antiárabe que prima en los medios de comunicación y en la adopción de acuerdos multilaterales entre las tres naciones, tal como lo hace la mayoría de gobiernos europeos, con el fin de detectar y contrarrestar la amenaza que representa eventualmente el yihadismo en la TF (Rebolledo, 2008, p.4).

En definitiva, la teoría plantea que los Estados deben buscar objetivos que no sean necesariamente racionales o utilitaristas $\mathrm{y}$, en su lugar, prolongar sus ideas hacia el exterior con el propósito de alcanzar intereses comunes con otros Estados a partir de la modificación de percepciones disonantes hacia temas claves en búsqueda de beneficios mutuos. Lo anterior, mediante el proceso de interacción de identidades que moldean las prácticas internacionales. Desde esta perspectiva, el constructivismo se centra en redefinir nuevos intereses e identidades, e institucionalizar nuevas relaciones sociales en el campo de las Relaciones Internacionales $y$, particularmente, en los procesos de integración de los actores sociales en el mundo internacional (Ovando y Álvarez, 2009).

En este marco, fuera de concebir los Estados de Suramérica bajo la lógica de que la amenaza por parte del grupos yihadistas está concentrada únicamente en la región de Medio Oriente, en el continente africano y europeo, se requiere establecer una mayor cooperación entre los gobiernos de la región para incrementar y explorar oportunidades inéditas para la integración regional orientadas al desarrollo de objetivos que apunten, primordialmente, a generar visiones compartidas sobre la seguridad y la defensa en el continente en relación con el nivel de riesgos que plantean en la región los grupos yihadistas. Es preciso generar medidas de prevención para revertir la posibilidad de que se desarrollen procesos de radicalización, ataques terroristas, la concentración de células durmientes y la financiación de grupos yihadistas en el continente americano, mediante el fomento de la interacción de identidades, socialización y aprendizaje mutuo entre los Estados, dejando de lado los cálculos egoístas y, en su lugar, el diálogo se encamine hacia formas de cooperación.

Por su parte, la globalización, que está determinada por el aumento de la interdependencia y de la actividad a través de las 
fronteras, presume la desaparición de las mismas. Esto lleva al desfavorecimiento del enfoque tradicional de la racionalidad sobre las amenazas a la seguridad y se implemente la cooperación entre los Estados en el debate de las fronteras (Rebolledo, 2008, p. 50).

\section{Plan contra la radicalización islamista}

Aunque el terrorismo yihadista no ha sido reconocido por los gobiernos sudamericanos como una amenaza real para el continente, sí existe una serie de vulnerabilidades que pueden ser aprovechadas por los grupos yihadistas que actualmente se encuentran operando internacionalmente como Hezbollah, el autodenominado Estado Islámico, Al Qaeda y sus afiliados, entre otros. Por ende, será primordial que, en las expectativas acerca de las estrategias antiterroristas que desarrollan los Estados, se incluya un plan dedicado a la prevención de la radicalización violenta, para eludir la aparición de personas en el continente dispuestos a morir y a matar por la yihad, lo cual muchas veces se escapa a los ojos de las autoridades. La intención será evitar estos movimientos antes de que se produzcan y que los Estados preparen medidas contra los extremismos.

Como se ha mencionado a lo largo del documento, este fenómeno representa una gran amenaza terrorista para el continente, pues muchas veces los llamados combatientes extranjeros regresan radicalizados a sus países de origen y pueden cometer atentados, teniendo en cuenta que según la agencia de inteligencia Soufan Group "al menos 76 personas de América del Sur, han viajado a Irak y Siria para unirse a Estado Islámico desde 2011" (Oppeinheimer, 2016).
El yihadismo no consiste solamente en la etapa final del lanzamiento de un ataque suicida o de otra especie, sino que incluye también que los combatientes que regresan puedan conspirar para proporcionar apoyo material a terroristas, adquirir experiencia operativa, tener vínculos con extremistas globales, predicar distorsionadamente el islam, reclutar jóvenes para su posterior adoctrinamiento y entrenamiento en campos especiales, recaudar fondos y armar células de apoyo logístico, entre otros. Por tal razón, los Estados deben incluir en su política doméstica y en especial los de Argentina, Brasil y Paraguay la comprensión e identificación del proceso de radicalización violenta y el terrorismo yihadista, con el propósito de obstruir las fuentes que mantienen las redes terroristas y de despojar a estas de una base social de apoyo.

Javier Jordán (2009), experto en procesos de radicalización afirma "que es por medio de este proceso que los individuos se incorporan a un sistema de creencias que incluye la voluntad de emplear o apoyar activamente la violencia, con el fin de alcanzar los objetivos del salafismo yihadista". Según un estudio realizado por el Real Instituto Elcano (2013), el proceso de yihadización es el siguiente:

1. Preradicalización: experiencia de agravio y deseo de aliviar el problema ("eso no está bien").

2. Autoidentificación con el radicalismo político: introducción de un criterio político/ético/religioso de referencia y experiencia de injusticia (“eso no es justo").

3. Adoctrinamiento y aislamiento social del grupo: identificación del agresor con un grupo determinado y culpabilizarían de ese grupo ("es culpa de..."). 
4. Yihadización y realización o planificación de actos terroristas: Solidificación del compromiso moral, íntimo y personal con el problema, demonización del enemigo y legitimización de la violencia política ("son malvados").

Así mismo, los Estados, en su política antiterrorista tendrán la responsabilidad de establecer unos objetivos estratégicos que se orienten a trabajar específicamente en los factores que favorecen a que actores no gubernamentales e individuos que apoyen al terrorismo y, por consiguiente, que favorezcan el reclutamiento terrorista de la siguiente manera:

1. Reconocer los elementos que contribuyen al reclutamiento terrorista a nivel nacional e internacional y desarrollar una estrategia a largo plazo para hacerles frente.

2. Investigar los enlaces entre las creencias religiosas y las políticas extremistas, los factores socioeconómicos que favorecen al yihadismo y el apoyo al terrorismo, con el fin de identificar las medidas adecuadas para contrarrestarlo.

3. Desarrollar e implementar una estrategia para fomentar la comprensión de culturas y religiones entre los países sudamericanos y el mundo islámico.

\section{Conclusiones}

El terrorismo internacional del siglo XXI empleado por los grupos yihadistas ha evidenciado ser superior con respecto a otros grupos, tanto en su estrategia, como en su estructura, organización y objetivos. Ciertamente, el yihadismo global ha logrado actuar en los últimos años por encima de las fronteras nacionales de los Estados y difundir actividades violentas en los medios masivos de comunicación para impresionar la mayor cantidad de población posible, por medio de la identificación de las vulnerabilidades, traducidas en términos de incapacidades, que tienen los países para contrarrestar amenazas terroristas. De hecho, organizaciones como Hamas, Hezbollah, Al Qaeda y el autodenominado Estado Islámico, emplean un repertorio de diferencias tácticas e instrumentos para la consecución de sus fines. Estas terminan representando una amenaza hibrida para la región de America Latina, pues recurren a una combinación de operaciones convencionales y guerra irregular, mezclada con acciones terroristas y conexiones con el crimen organizado.

Si bien la fase de expansión rigorista del islam radical aún no se ha establecido de manera formal en America Latina y que hasta ahora es la región del mundo con menor riesgo de acciones terroristas, no sobra tener en cuenta que el radicalismo conquista en zonas vulnerables, receptivas al clientelismo, en donde prosperen actividades ilícitas y donde se localice el crimen organizado, permeado por la corrupción. A partir de ello, la TF es considerada es el lugar más propenso a concentrar la amenaza yihadista en el Cono Sur, donde las mafias de las diferentes etnias, no solo árabe sino también la china, las organizaciones de crimen organizado y la corrupción son los mayores peligros para que la TF sea un campo abonando para los grupos yihadistas en la región.

Finalmente, es fundamental que los países involucrados superen las limitaciones analíticas en cuanto al caos de la $\mathrm{TF}$, ya que es 
un caso múltiple, donde la violencia es evidente y la situación se torna muy compleja. Por ello, los Estados deben concentrar los esfuerzos en el ámbito nacional, pero también establecer medidas de cooperación con otros Estados de la región para la erradicación del yihadismo y hacer énfasis en los mecanismos de socialización que emplean estos grupos, ya que es por medio de estos que los grupos yihadistas trasmiten sus valores. Además, se debe hacer omisión a las teorías conspirativas que orientan hacia la lucha contra el islam y, por el contrario, promover la integración identitaria de las comunidades musulmanas. Esto es imprescindible para la prevención de la radicalización, con el fin de que los inmigrantes musulmanes y los conversos se sientan miembros de una misma sociedad.

De igual forma, limitar el accionar de los grupos radicales articulando con los Estados medidas legales y administrativas que eludan los trabajos de captación que realizan estos grupos orientados por los servicios de información policiales y los servicios de inteligencia, para obtener alertas tempranas sobre la presencia del yihadismo en la TF.

\section{REFERENCIAS}

Alda, S. (2014). Un campo abonado para el crimen organizado. Foreing Affairs Latinoamérica. V. 14, 1, pp. 57-64

Al- Islam. (s.f). La vida de Muhammad el profeta. Recuperado de https://www. al-islam.org/es/la-vida-de-muhammad-el-profeta-sayyed-saeed-akhtar-rizvi/cap\%C3\%ADtulo-13-otras-batallas\#la-batalla-de-uhud
Alonso, R. (2015). El terrorismo yihadista: una amenaza hibrida. Fundación para el análisis y los estudios sociales, pp. 63-80.

Andrade, G. (2001). Posibilidades de crecimiento del Islam en América Latina: oportunidades y dificultades. Revista Scielo, pp. 117,132, Recuperado de http://webcache.googleusercontent. com/search?q=cache:QdpaY8ino9cJ:www.produccioncientifica.luz.edu. ve/index.php/opcion/article/download $/ 6224 / 6212+\& \mathrm{~cd}=1 \& \mathrm{chl}=\mathrm{es} \& \mathrm{ct}=\mathrm{cl}-$ $\mathrm{nk} \& \mathrm{gl}=\mathrm{CO}$

Bartolomé, M (2002). La Triple Frontera: principal foco de inseguridad en el Cono Sur Americano. Military Review, v. 82, (4), pp. 61-74.

BBC. (17 marzo 2005). Árabes y musulmanes en América Latina. Diario BBC. Recuperado de http://news.bbc.co.uk/hi/spanish/specials/newsid_4294000/4294241.stm

Bello, D. (2013). La triple frontera como polo de atracción de actividades ilícitas: condiciones endógenas insitucionales e ilegalidad. Revista Atenea, http://dx.doi. org/10.4067/S0718-04622013000200008, pp. 101-120.

Bello, D. (2015). Construcción de la realidad a través de los medios de comunicación: terrorismo islámico, intereses geopolíticos y criminalidad en la Triple Frontera del Paraná. Revista Anagramas, Medellín, v.13, (26), pp. 115-136.

Callejas, A. (2016). Islam, yihad, salafismo. Glosario clave para entender la religión musulmana. Diario 20 minutos. Recuperado de http://www.20minutos.es/ noticia/2778610/0/significado-islam-yihad-salafismo-glosario-musulmanes/

Caro, I. (2007), “Identidades Islámicas Contemporáneas en América Latina”, Revista Universum, Talca, v. 2, (22), pp. 27-39. 
Center For Security Free Society. (2014). Como opera la red financiera de Hezbollah en América Latina. Recuperado de http://www.securefreesociety.org/ publications/como-pera-la-red-financiera-de-hezbollah-en-america-latina/

Cesio, P. (23 enero 2016). El Islam avanza en América Latina. Aleteia. Recuperado de http://es.aleteia.org/2016/01/23/ el-islam-avanza-en-america-latina/.

Comunidad Musulmana Ahmadiyya. (s.f). Yihad o Terrorismo? Una perspectiva Islámica. Recuperado de http://www. islamahmadiyya.es/publicaciones/folletos/yihad_o_terrorismo.pdf

El País. (s.f). Orientales del Islam. Diario El País. Recuperado de http://www.elpais. com.uy/que-pasa/orientales-islam.html

Fogel, Ramón. (2008). La región de la triple frontera: territorios de integración y desintegración. Revista Sociologías. Porto Alegre, v.10, (20), pp. 270-290.

Fuente, I. (2014). La amenaza hibrida: yihadismo y crimen organizado en el Sahel. Instituto Español de Estudios Estratégicos. Recuperado de http://www.ieee. es/Galerias/fichero/docs_analisis/2014/ DIEEEA57-2014_AmenazaHibridaSAHEL_IFC.pdf

Fleischman, Luis, (2015). In Latin America, radical Islamic presence flourishes while key countries downplay the threat. Washington, United States.

Keshavarz, A. (2015). Irán and Hezbollah in the Tri-Border Areas of Latin America: A Look at the ?Old TBA? And the ?New TBA? Small Wars Journal

International Organization for Migration. (s.f). Lucha contra la trata de personas en la Triple Frontera. Recuperado de http:// argentina.iom.int/co/lucha-contra-la-trata-de-personas-en-la-triple-frontera
Jordán, J. (2009). Procesos de radicalización yihadista en España: análisis sociopolítico en tres niveles. Revista de Psicología Social. Recuperado de http://www.ugr. es/ jjordan/publicaciones/radicalizacion.pdf

Lacomba, J. (2001). Teorías y prácticas de la inmigración. de los modelos explicativos a los relatos y proyectos migratorios. Revista electrónica de Geografía y Ciencias Sociales. Barcelona, v.11, (94).

Lide, S. (2016). CDE sin fronteras. Recuperado de http://www.abc.com.py/edicion-impresa/opinion/cde-sin-fronteras-1490875.html

Louise, S \& Picarelli, J. (2002). Methods not motives: implications of the convergence of international organized crime and terrorism. Recuperado de https://www. ncjrs.gov/pdffiles1/nij/grants/211207. pdf

Manassero, María. (2008), “El Neo-fundamentalismo islámico y el $11 \mathrm{~s}$ ", Centro argentino de Estudios internacionales, Working paper \# 20, pp. 2-12

Marin, I. (2015). La relación entre el Crimen Organizado Transnacional en la Triple Frontera y la Política Exterior de seguridad de Brasil, Argentina Y Paraguay entre 1996 Y 2006. Repositorio Universidad del Rosario. Recuperado de http:// repository.urosario.edu.co/bitstream/ handle/10336/11666/1020769948\%20 -\%202015.pdf?sequence $=1$

Miami Herald. (Noviembre 23 de 2015). Radical Islam's Latin American connection. Recuperado de http://www.miamiherald.com/opinion/op-ed/article46127140. html

Oppenheimer, A. (2016) “¿Atacará IS en América Latina?" en El Mundo. Recuperado de http:/www.elmundo.es/ 
internacional/2016/04/05/5702844a46163f05428b4597.html

Organización Islámica para América Latina (2006), http://www.islamerica.org.ar/ oipal.htm Consulta: Septiembre 2, 2016. Rebolledo, J. (2008), “Fronteras porosas: El caso de México y Estados Unidos. Revista Enfoques, Miami, v. 6, (8), pp. 173-191

Sánchez, F. (2011). Evolución del régimen de control y financiación del terrorismo. Revista de Relaciones Internacionales, Estrategia y Seguridad. Bogotá, v. 6, (2), pp. 21-34

Schulmeiste, G. (2004). Triple Frontera: Donde confluyen una multiplicidad de factores y problemáticas de la seguridad. Informe Fundación Justicia y Seguridad.
Recuperado de https://wikileaks.org/gifiles/attach/174/174095_Triple\%20Frontera.pdf

Sohr, R. (2015). El terrorismo yihadista. Santiago de Chile, Chile: Penguin Random House Grupo Editorial Chile.

Transparency International. (2015). Paraguay: Overview of corruption and anti-corruption. Recuperado de http:// www.transparency.org/whatwedo/ answer/paraguay_overview_of_corruption_and_anti_corruption

Torres, Manuel. (2007), “La dimensión propagandística del terrorismo yihadista global", España, editorial de la Universidad de Granada, pp. 1-479. 